\title{
Etiological Factors of Recurrent Aphthous Stomatitis: A Common Perplexity
}

Niharika Swain, Jigna Pathak, Leela S Poonja, Yogita Penkar

\section{ABSTRACT}

Recurrent aphthous stomatitis (RAS) is one of the most common oral mucosal disorders. Nevertheless, while the clinical characteristics of RAS are well-defined, the precise etiology and pathogenesis of RAS remain unclear. The present article provides a detailed review of the current knowledge of various etiological factors of RAS.

Keywords: Mouth ulcers, Recurrent aphthous stomatitis, Etiology.

How to cite this article: Swain N, Pathak J, Poonja LS, Penkar Y. Etiological Factors of Recurrent Aphthous Stomatitis: A Common Perplexity. J Contemp Dent 2012;2(3):96-100.

Source of support: Nil

Conflict of interest: None declared

\section{INTRODUCTION}

Recurrent aphthous stomatitis (RAS; Aphthae; Canker sores), a common oral mucosal disorder that is characterized by multiple, recurrent, small, round or ovoid ulcers with circumscribed margins, erythematous haloes, and yellow or gray floors that present first in childhood or adolescence. Although it is one of the most common recurrent oral ulcerative conditions of adults and children recognized throughout the world, RAS is also one of the least understood oral diseases and is among the most vexing problems faced by affected patients and clinicians alike. ${ }^{1,2}$ The triggering factors that precipitate recurrent episodes in RAS patients seem to be as diverse and unique as the affected individuals themselves, which has posed a challenge for researchers in their attempts to identify a specific causation for this disease. Although the exact etiology of RAS remains obscure, there is growing lucidity with regard to its pathogenesis which has significantly influenced contemporary approaches toward its management. This article reviews the clinical features and various etiological factors of RAS.

\section{CLINICAL FEATURES}

'Aphthous' comes from the Greek word 'aphtha', which means ulcer. Despite the redundancy, the medical literature continues to refer to these oral lesions as aphthous ulcers. 'Aphthous stomatitis' has been used interchangeably with 'aphthous ulcers' and may be a more accurate terminology. Aphthous ulcers are round or oval, with a grayish yellow, crateriform base surrounded by an erythematous halo of inflamed mucosa. For 24 to 48 hours preceding the appearance of an ulcer, most patients have a pricking or burning sensation in the affected area. The ulcer usually occurs on the nonkeratinized oral mucosa, including the lips, the buccal mucosa, floor of the mouth, soft palate and the ventral surface of the tongue.

RAS is seen worldwide and may affect up to $25 \%$ of the population. ${ }^{1-3}$ Recurrent aphthous ulceration has three different variants—minor aphthous ulcers, major aphthous ulcers and herpetiform ulcers, according to the classification described by Stanley ${ }^{4}$ in 1972. Minor RAU (MiRAU) is the common variety, affecting about $80 \%$ of RAU patients. It is characterized by painful round or oval shallow ulcers, regular in outline, less than $10 \mathrm{~mm}$ in diameter, with a graywhite pseudomembrane surrounded by a thin erythematous halo. MiRAU usually occurs on nonkeratinized mucosa such as labial mucosa, buccal mucosa and floor of the mouth. It is uncommon on the keratinized mucosa. Minor RAU is the most common form of childhood RAU. The lesions recur at varying frequencies (from every few years to almost constantly) and heal within 7 to 10 days without scarring. Major RAU (MaRAU), also known as periadenitis mucosa necrotica recurrens, occurs in approximately $10 \%$ of RAU patients. The lesions are similar in appearance to those of minor RAU, but they are larger than $10 \mathrm{~mm}$ in diameter, single or multiple and very painful. MaRAU has a predilection for the lips, soft palate, and fauces, but can affect any site. The ulcers of MaRAU persist for up to 6 weeks or longer and often heal with scarring. Herpetiform aphthae accounts for 7 to $10 \%$ of all RAU cases. In herpetiform RAU there are 10 to 100 ulcers at a time, ulcer size is usually 1 to $3 \mathrm{~cm}$, and the ulcers form clusters that coalesce into widespread areas of ulceration lasting 7 to 10 days. These ulcers are only herpes-like in appearance; herpes simplex virus has not been cultured from them.

\section{ETIOLOGY}

To date, the precise etiology of RAS has not been disclosed, despite years of collective effort on the part of many researchers. Historically, conjecture about the origin of RAS focused on a wide spectrum of potential local and systemic factors that encompassed microbial agents, hematologic and hormonal disturbances, physical injury, emotional stress and other influences. Also confounding the search for a singular 
cause is the observation that aphthous-like oral ulcers often occur in conjunction with diverse conditions of a systemic nature. Included among those conditions are cyclic neutropenia, selected anemias, ${ }^{5}$ inflammatory bowel diseases, ${ }^{6}$ Behçet's disease, ${ }^{7,8}$ gluten-sensitive enteropathy (celiac sprue), ${ }^{9,10}$ relapsing polychondritis syndromes (including the so-called 'MAGIC' syndrome, which consists of mouth and genital ulcers with inflamed cartilage), ${ }^{11} \mathrm{HIV}$ infection, ${ }^{12}$ the purported symptom complex of recurring fevers, aphthous stomatitis, pharyngitis and lymphadenopathy (FAPA syndrome). ${ }^{13}$

In recent years, body of evidence has emerged to suggest a genetic and an immunologic basis for RAS. These revelations largely have eclipsed speculation that RAS is caused by an infectious microorganism or one of the other previously suspected etiologic factors. They also have led to more rational and effective contemporary approaches to the management of RAS.

\section{Genetic Factors}

Some people have a well-established familial basis for RAU. As compared to the general population, the prevalence of RAS is higher when there is a positive family history, especially when both parents are affected. There is also increased disease correlation observed in identical twins as compared to fraternal twins. In familial cases of RAS, the onset of disease is earlier and attacks tend to occur more frequently than in nonfamilial cases. ${ }^{14-16}$ The likelihood that RAS is a genetically grounded disease is further supported by the recognized, although not entirely consistent, identification of certain histocompatibility antigen (HLA) types (e.g. HLA B12, B51, Cw7), among some groups of aphthous patients. ${ }^{17}$

\section{Immunologic Factors}

Despite the inconsistent finding and conflicting theories, mounting scientific evidences support immune dysregulation as a key mechanism underlying the pathogenesis of RAS. It is believed that the altered immune reactivity arises perhaps in response to, or in concert with, a state of presumably heightened antigenic stimulation ${ }^{18}$ exacted on a diminished mucosal barrier. A constellation of cellmediated immunologic phenomena seems to be a consistent factor in the disease. Serologic studies that compared RAS patients and unaffected controls revealed diminished ratios of circulating $\mathrm{CD}^{+}$helper cells to $\mathrm{CD}^{+}{ }^{+}$suppressor cells in the former group. ${ }^{19,20}$ It has been proposed that in RAS some unspecified antigenic influence ${ }^{21}$ is at the epicenter of an antibody-dependent, T cell-mediated immune response that involves a shift in local lymphocytic subpopulations that eventuates in tissue damage. ${ }^{22-24}$ From the observations of several investigators it has been hypothesized that the entire process of aphthous ulceration, from initiation through progression, is instigated by the expression on oral epithelial cells of not only normally found HLA class I antigens but also HLA class II antigens. ${ }^{25}$ Presumably, this renders the cells antigenically 'foreign' and consequently they become the targets of a cell-mediated immune reaction perpetrated by lymphocytes and Langerhans cells. It has been shown that in patients with aphthous stomatitis there is a heightened lymphocytotoxic effect directed against oral epithelial cells when compared to unaffected controls. ${ }^{24-26}$

Evidence for this pathogenetic mechanism is also inferred from observations that tissue biopsies of newly erupted aphthous ulcerations demonstrate agglomeration of activated $\mathrm{T}$ lymphocytes at the periphery of the lesions, whereas in well-established aphthae the initially predominant $\mathrm{CD} 4^{+}$helper/suppressor cell population is subsumed and succeeded by cytotoxic CD8 ${ }^{+}$lymphocytes. ${ }^{23,24}$ Additional indirect support for primary immune dysregulation is reflected in the long-recognized correlation between stress and outbreaks of aphthous ulcers that is reported by many RAS patients, in contrast to the notable decrease in frequency of episodes during periods of reduced stress. ${ }^{27}$ This observed association is not entirely surprising, because stress is known to affect immunologic function. It also has been observed that HIV-infected patients experience oral aphthous-like ulcerations with relatively high frequency. With advancing immune depletion, their aphthous outbreaks are often dominated by larger ulcers that run a more protracted course. ${ }^{28,29}$ Attempts to explore the possibility that RAS is fundamentally an antibody-driven disorder have disclosed findings that are at best inconsistent and largely unsupportive. It seems that any previously held conjecture that aphthous ulcers stem from a centrally generated humoral immune mechanism rather than from local cellular immune responses to an antigenically modified oral mucous membrane was predicated on assumptions that have since been discredited. ${ }^{17,30-32}$

\section{Microbial Factors}

There is little consistent evidence to support the hypothesis that RAS represents an infectious disease. In particular, from studies to determine whether there might be a connection between previously suspect L-forms of streptococci and RAS, or the adenoviruses, herpes simplex virus (HSV), varicella-zoster virus, or cytomegalovirus and RAS, the available evidence suggests that none of these microorganisms seems to be directly culpable for RAS despite continued speculation about their possible role. One should note that an antiviral agent, acyclovir, offers no beneficial effect in preventing or attenuating episodic flares of the 
condition, ${ }^{33}$ which serves to weaken arguments in favor of a possible viral causation for RAS. From occasional anecdotal cases in which patients report an apparent consistent temporal relationship between their aphthous outbreaks and an immediately antecedent reactivated (recurrent) HSV infection, it is tempting to postulate that in a narrow subset of individuals who get RAS, the herpes virus may serve as an antigenic 'trigger' that initiates the cascade of immunologic events that result in ulceration. In a limited subset of RAS patients, it is possible that this is actually the case. Presumably, such patients would benefit from appropriate therapeutic and prophylactic antiviral therapy, coupled with treatments specifically aimed at lessening the severity and frequency of the RAS episodes by modulating their supposedly heightened immune responses to the viral 'trigger'. Such therapeutic strategies probably would be best carried out in consultation with an infectious disease specialist. It must be emphasized, however, that regarding most aphthous patients, any suggestion of a causative nexus between RAS and HSV seems to represent unsubstantiated conjecture rather than proven fact. ${ }^{34,35}$

\section{Nutritional Factors}

Other issues explored in the quest to determine a cause for RAS include the possible relationship of attacks to excess or deficiency of various nutritional factors, such as serum iron, folate and vitamin $\mathrm{B}_{12}$, and speculation that aphthous ulcers represent the manifestation of an allergic reaction to certain foods or other ingested or contacted substances. Apart from variably favorable responses to the avoidance of gluten products in aphthous patients with documented intestinal malabsorption disease (compared to controls ${ }^{36}$ and in some aphthous stomatitis patients with normal intestinal function, ${ }^{37}$ evidence that RAS primarily represents an allergic response or is etiologically linked to diminished serum iron, vitamin $\mathrm{B}_{12}$ or folate levels is lacking or, at best, equivocal. ${ }^{23,27,38}$ For any RAS patient who exhibits physical signs and symptoms that suggest the possibility of an underlying malabsorption or nutritional deficiency state or a blood dyscrasia, it is prudent to obtain a complete blood count and assays for serum folate, vitamin $\mathrm{B}_{12}$ and ferritin. Should any of these tests yield findings that suggest an underlying systemic abnormality, referral to an internist or a hematologist is indicated.

The improvement of RAU with zinc sulfate supplementation has been described in an open trial ${ }^{39}$ and in a case report of aphthous ulcers with zinc deficiency and immunodeficiency, ${ }^{40}$ but such improvement was not been confirmed in later studies. ${ }^{41,42}$ In a Chinese study the level of serum zinc in 75 cases of RAU was found to be at a low level but, within the normal range, and serum copper levels were also normal. ${ }^{43}$ So far no information exists on the associations between RAU and other trace elements.

\section{Environmental Factors}

\section{Stress}

Earlier studies have documented an association between RAU and a variety of psychological factors including anxiety, repressed hostility, as well as job-related and other stress factors. Conversely, other studies have failed to reveal any association between anxiety, depression, psychological life stress and recurrences of RAU. In one study, in which a relaxation/imagery treatment program was used, a significant decrease in the frequency of ulcer recurrence among all treated subjects was noted ${ }^{44}$ Although the majority of investigators have been unable to validate the concept that stress plays an important role in the development of RAU, the literature continues to indicate that stress may play a role in precipitating RAU.

\section{Local Trauma}

A subset of patients with RAU is predisposed to develop aphthae at sites of trauma. The reason why local trauma, such as anesthetic injections, sharp foods, tooth-brushing and dental treatment, can trigger aphthous ulceration in these patients is still unknown. ${ }^{45}$

\section{Tobacco}

Several investigators have documented a negative association between smoking and the occurrence of RAU. ${ }^{46}$ Such a negative association has also been documented as regards the use of smokeless tobacco (chewing tobacco and snuff), as well as in patients who are smokers. ${ }^{47}$ Paradoxically, the majority of patients with RAU are nonsmokers, and in a recent study only $9 \%$ of RAU patients were found to be active smokers, compared with $25 \%$ among the control subjects. ${ }^{48}$

Nicotine has been reported to be beneficial in RAU and in inflammatory bowel disease, and its effects may result from influences on nerve function, although these may also exert direct anti-inflammatory effects. However, the mechanism by which cigarette smoking protects against RAU is still unknown.

\section{Food Hypersensitivity}

Some investigators have correlated the onset of ulcers to exposure to certain foods, such as cows' milk, gluten, chocolate, nuts, cheese, azo dyes, flavoring agents and preservatives. Eversole et al (1982) found no significant association between RAU and three specific food items 
(tomatoes, strawberries and walnuts). ${ }^{49}$ Some investigators have noted an increased prevalence of atopy among RAU patients, whereas Wray et al (1982) found no significant difference in the incidence of atopy in RAU patients compared with the normal population. ${ }^{50}$

\section{Drugs}

Some drugs, such as nonsteroidal anti-inflammatory drugs (NSAIDs, e.g. proprionic acid, phenylacetic acid and diclofenac) can give rise to oral ulcers similar to those of RAU, along with genital ulceration or only oral ulcers in the case of piroxicam. ${ }^{51}$ An association between betablockers and aphthous ulcers has also been suggested. Such ulcers usually occur as an adverse side effect and disappear with discontinued usage of the drug. ${ }^{52,53}$

Recently, an increased frequency in the occurrence of RAS has been reported on using sodium lauryl sulfate (SLS)containing toothpaste. Some reduction in ulceration has been noticed on use of SLS-free toothpaste. However, because of the widespread use of SLS-containing dentifrice, it has been proposed that this may not be a true predisposing factor of RAS. ${ }^{54}$

\section{CONCLUSION}

While RAS remains a common oral mucosal disorder in most communities of the world, its precise etiology remains unclear. No precise trigger has ever been demonstrated, and there is no conclusive evidence for a genetic predisposition to RAS in most patients. Currently, RAS is recognized as an immunologically mediated, inflammatory oral condition rather than an infectious disease. It is reasonable to suggest that for the future, anticipated new insights into the condition's origin and pathogenesis, combined with ongoing research directed toward the development of safer, more effective immunomodulating agents, render the prospect of a cure for RAS increasingly plausible.

\section{REFERENCES}

1. Jurge S, Kuffer R, Scully C, Porter SR. Number VI recurrent aphthous stomatitis. Oral Dis 2006;12:1-21.

2. Scully C. Aphthous ulceration. N Engl J Med 2006;355:165-72.

3. Ship II. Epidemiologic aspects of recurrent aphthous ulcerations. Oral Surg Oral Med Oral Pathol 1972;33:400-06.

4. Stanley HR. Aphthous lesions. Oral Surg Oral Med Oral Pathol Oral Radiol Endod 1972;33:407-16.

5. Ship JA, Chavez EM, Doerr PA, et al. Recurrent aphthous stomatitis. Quintessence Int 2000;31:95-112.

6. Glickman RM. Inflammatory bowel disease: Ulcerative colitis and Crohn's disease. In: Fauci AS, Braunwald E, Isselbacher KJ, et al (Eds). Harrison's principles of internal medicine (14th ed). New York: McGraw-Hill 1998:1633-45.

7. Ghate JV, Jorizzo JL. Behçet's disease and complex aphthosis. J Am Acad Dermatol 1999;40:1-18.
8. International Study Group for Behçet’s Disease. Criteria for diagnosis of Behcet's disease. Lancet 1990;335:1078-80.

9. Magro C, Crowson AN, Mihm M. Cutaneous manifestations of nutritional deficiency states and gastrointestinal disease: Behçet's disease, inflammatory bowel diseases (Crohn's disease, ulcerative colitis, celiac disease). In: Elder D, Elenitsas R, Jaworsky C, Johnson B, (Eds). Lever's histopathology of the skin (8th ed). Philadelphia: Lippincott-Raven 1997:359-63.

10. Rizzi R, Bruno S, Dammacco R. Behçet’s disease: An immunemediated vasculitis involving vessels of all sizes [review]. Int J Clin Lab Res 1997;27:225-32.

11. Eisenberg E. Diagnosis and treatment of recurrent aphthous stomatitis. Oral Maxillofacial Surg Clin N Am 2003;15:111-22.

12. Ficarra G. Oral ulcers in HIV-infected patients: An update on epidemiology and diagnosis [review]. Oral Dis 1997; 3(Suppl 1):S183-89.

13. Marshall GS, Edwards KM, Butler J, et al. Syndrome of periodic fever, pharyngitis and aphthous stomatitis. J Pediatr 1987;110: 43-46.

14. Ship JA. Inheritance of aphthous ulcers of the mouth. J Dent Res 1965;44:837-44.

15. Miller MF, Garfunkel AA, Ram CA, et al. Inheritance patterns in recurrent aphthous ulcers: Twin and pedigree data. Oral Surg Oral Med Oral Pathol 1977;43: 886-91.

16. Miller MF, Garfunkel AA, Ram CA, et al. The inheritance of recurrent aphthous stomatitis. Oral Surg OralMed Oral Pathol 1980;49:409-12.

17. Neville BW, Damm DD, Allen CM, Bouquot JE. Allergies and immunologic diseases: Recurrent aphthous stomatitis. In: Oral and maxillofacial pathology (2nd ed). Philadelphia: WB Saunders 2002:285-90.

18. Vincent SD, Lilly GE. Clinical, historic, and therapeutic features of aphthous stomatitis: Literature review and open clinical trial employing steroids. Oral Surg Oral Med Oral Pathol 1992;74: 79-86.

19. Landesberg R, Fallon M, Insel R. Alterations of T-helper/inducer and T-suppressor/inducer cells in patients with aphthous ulcers. Oral Surg Oral Med Oral Pathol 1990;69:205-08.

20. Savage NW, Mananonda R, Seymour GJ, et al. Theproportion of suppressor-inducer T-lymphocytes is reduced in recurrent aphthous stomatitis. J Oral Pathol Med 1988;17:293-97.

21. Schroeder HE, Muller-Glauser W, Sallay K. Stereological analysis of leukocyte infiltration in oral ulcers of developing Mickulicz aphthae. Oral Surg Oral Med Oral Pathol 1983;56: 629-40.

22. Greenspan JS, Gadol N, Olson JA, et al. Antibody dependent cellular cytotoxicity in recurrent aphthous ulceration. Clin Exp Immunol 1981;44:603-10.

23. Pedersen A, Hougen P, Kenrad B. T-lymphocyte subsets in oral mucosa of patients with recurrent aphthous ulceration. J Oral Pathol Med 1992;21:176-80.

24. Savage NW, Seymour GJ, Kruger BJ. T-lymphocyte subset changes in recurrent aphthous stomatitis. Oral Surg Oral Med Oral Pathol 1985;60:175-80.

25. Savage NW, Seymour GJ, Kruger BJ. Expression of class I and class II major histocompatibility complex antigens on epithelial cells in recurrent aphthous stomatitis. J Oral Pathol Med 1986;15: 191-95.

26. Rogers RS, Sams WM, Shorter RG. Lymphocytotoxicity in recurrent aphthous stomatitis. Arch Dermatol 1974;109:361-63.

27. Woo SB, Sonis ST. Recurrent aphthous ulcers: A review of diagnosis and treatment. J Am Dent Assoc 1996;127:1202-13. 
28. MacPhail LA, Greenspan JS. Oral ulceration in HIV infection: Investigation and pathogenesis. Oral Dis 1997;3(Suppl 1): S190-93.

29. Phelan JA, Eisig S, Freedman PD, et al. Major aphthous- like ulcers in patients with AIDS. Oral Surg Oral Med Oral Pathol 1991;71:68-72.

30. Cohen L. Etiology, pathogenesis and classification of aphthous stomatitis and Behçet’s syndrome. J Oral Pathol 1978;7:347-52.

31. Lehner T. Immunologic aspects of recurrent oral ulcers. Oral Surg Oral Med Oral Pathol 1972;33:80-85.

32. Ben Aryeh H, Malberger E, Gutman D, et al. Salivary IgA and serum IgG and IgA in recurrent aphthous stomatitis. Oral Surg Oral Med Oral Pathol 1976;42:746-52.

33. Wormser GP, Mack L, Lenox T, et al. Lack of effect of oral acyclovir on prevention of aphthous stomatitis. Otolaryngol Head Neck Surg 1988;98:14-17.

34. Kameyama T, Sujaku C, Yamamoto S, et al. Shedding of herpes simplex virus type I into saliva. J Oral Pathol 1988;17:478-81.

35. Neville BW, Damm DD, Allen CM, Bouquot JE. Viral infections: HSV, VZV, CMV. In: Oral and maxillofacial pathology (2nd ed). Philadelphia: WB Saunders 2002:213-24.

36. Veloso FT, Saleiro JV. Small-bowel changes in recurrent ulceration of the mouth. Hepatogastroenterology 1987;34:36-37.

37. Wray D. Gluten-sensitive recurrent aphthous stomatitis. Dig Dis Sci 1981;26:737-40.

38. Olson JA, Feinberg I, Silverman S Jr, et al. Serum vitamin $B_{12}$, folate and iron levels in recurrent aphthous stomatitis. Oral Surg Oral Med Oral Pathol 1982;54:517-20.

39. Merchant HW, Gangarosa LP, Glassman AB, Sobel RE. Zinc sulphate supplementation for the treatment of recurring oral ulcers. South Med J 1977;70:559-61.

40. Endre L. Recurrent aphthous ulceration with zinc deficiency and cellular immune deficiency. Oral Surg Oral Med Oral Pathol Oral Radiol Endod 1991;72:559-61.

41. Merchant HW, Gangarosa LP, Morse PK, Strain WH, Baisden CR. Zinc sulphate as a preventive of recurrent aphthous ulcers. J Dent Res 1981;60A:609.

42. Wray D. A double-blind trial of systemic zinc sulfate in recurrent aphthous stomatitis. Oral Surg Oral Med Oral Pathol Oral Radiol Endod 1982;53:469-72.

43. Pang JF. Relation between treatment with traditional Chinese medicine for recurrent aphthous ulcer and human zinc and copper. Zhongguo Zhong Xi Yi Jie He Za Zhi 1992;12:280-82.

44. Andrews VH, Hall HR. The effect of relaxation/imagery training on recurrent aphthous stomatitis: A preliminary study. Psychosom Med 1990;52:526-35.

45. Wray D, Graywoski EA, Notkins AL. Role of mucosal injury in initiating recurrent aphthous ulceration. Br Med J 1981;283:1569-70.
46. Shapiro S, Olsson DL, Chellemi SJ. The association between smoking and aphthous ulcers. Oral Surg Oral Med Oral Pathol Oral Radiol Endod 1970;30:624-30.

47. Grady D, Ernster VL, Stillman L, Greenspan J. Smokeless tobacco use prevents aphthous stomatitis. Oral Surg Oral Med Oral Pathol Oral Radiol Endod 1992;74:463-65.

48. Tuzun B, Wolf R, Tuzun Y, Serdaroglu S. Recurrent aphthous stomatitis and smoking. Int J Dermatol 2000;39:358-60.

49. Eversole LR, Shopper TP, Chambers DW. Effects of suspected foodstuff challenging agents in the etiology of recurrent aphthous stomatitis. Oral Surg Oral Med Oral Pathol Oral Radiol Endod 1982;54:33-38.

50. Wray D, Vlagopoulus TP, Siraganian RP. Food allergens and basophil histamine release in recurrent aphthous stomatitis. Oral Surg Oral Med Oral Pathol Oral Radiol Endod 1982;54:388-95.

51. Seigel MA, Balciunas BA. Medication can induce severe ulceration. J Am Dent Assoc 1991;122:75-77.

52. Natah SS, Konttinen YT, Enattah NS, Ashammakhi N, Sharkey KA, Häyrinen-Immonenb R. Recurrent aphthous ulcers today: A review of the growing knowledge. Int J Oral Maxillofac Surg 2004;33:221-34.

53. Eisenberg E. Diagnosis and treatment of recurrent aphthous stomatitis. Oral Maxillofacial Surg Clin N Am 2003;15:111-22.

54. Preeti L, Magesh KT, Rajkumar K, Karthik R. Recurrent aphthous stomatitis. J Oral Maxillofac Pathol 2011 SepDec;15(3):252-56.

\section{ABOUT THE AUTHORS}

\section{Niharika Swain (Corresponding Author)}

Lecturer, Department of Oral Pathology, MGM Dental College and Hospital, Navi Mumbai, Maharashtra, India e-mail: niharikadec30@gmail.com

\section{Jigna Pathak}

Professor, Department of Oral Pathology, MGM Dental College and Hospital, Navi Mumbai, Maharashtra, India

\section{Leela S Poonja}

Professor, Department of Oral Pathology, MGM Dental College and Hospital, Navi Mumbai, Maharashtra, India

\section{Yogita Penkar}

Lecturer, Department of Oral Pathology, MGM Dental College and Hospital, Navi Mumbai, Maharashtra, India 